Central European Journal of Energetic Materials, 2016, 13(1), 117-134

ISSN 1733-7178

e-ISSN 2353-1843

\title{
Experimental Study of the Explosion of Aluminized Explosives in Air
}

\author{
Yuan CHEN, Sen XU, De Jun WU, Da Bin LIU* \\ School of Chemical Engineering, \\ Nanjing University of Science \& Technology, \\ Xiaoling Wei, 200, Xuan Wu, Nanjing, P.R. China \\ *E-mail:iem_liu@163.com
}

\begin{abstract}
Piezoelectric gauges were used to measure the shock wave overpressure of aluminized explosives and of a TNT charge. An infrared thermal-imaging spectrometer was used to collect the infrared signatures produced by the explosion fireball when the examined explosives were detonated. The measurement of the infrared signatures was used to estimate the surface temperatures and the dimensions of the fireball. Two aluminized explosive compositions (RDX/Al/AP and $\mathrm{RDX} / \mathrm{Al} / \mathrm{B} / \mathrm{AP}$ ) have been analyzed. $500 \mathrm{~g}$ charges of the aluminized explosives were prepared and studied, and their TNT equivalences were calculated according to the experimental data and the explosion law. The highest surface temperatures of the fireballs of these aluminized explosives were up to $1600^{\circ} \mathrm{C}$, which was higher than that of the TNT charge. In the region of the highest surface temperature above $700{ }^{\circ} \mathrm{C}$, the duration for the composition RDX/A1/AP was about $232 \mathrm{~ms}$ (2.73 times more than TNT), whilst RDX/Al/B/AP was about $360 \mathrm{~ms}$. The fireballs obtained from the explosion of these aluminized explosives had larger dimensions than that of TNT, especially when the surface temperature was above $1000{ }^{\circ} \mathrm{C}$. The test results indicate that the addition of boron powders to aluminized explosives is a good way to enhance their blast effect, to improve the temperature of the explosion field and to prolong the duration of the higher temperature.
\end{abstract}

Keywords: explosion in air, aluminized explosives, boron powders, TNT equivalence, fireballs

\section{Introduction}

Metal powders with high heats of combustion are of interest as high energy density materials. These powders are added to blast explosives and propellants 
to act as fuels. One such common powder additive is aluminum. Aluminized explosives have been used in various formulations since the beginning of the 20th century. Aluminum powders are added to explosives to enhance their blast effect, and to increase the bubble energies in underwater explosions [1-3].

Aluminized explosives are non-ideal, and the aluminum particles can react with the explosive detonation products, which improve the explosives, with the advantage of higher heat of detonation, higher temperature of explosion, and longer energy release time [4-6]. Sequential reaction zones may depend on particle size and other factors [7]. There are many practical applications and a large number of studies devoted to the effect of particle size, aluminum content and other factors on aluminized explosive [8-12]. With decreasing particle size of the aluminum powder, the detonation velocity is decreased and the heat of explosion is increased. Nano-metric aluminum has become available for introduction into explosives, and a lot of work has been accomplished recently [13-19]. However, nano-metric aluminum has no significant advantages over micro-metric aluminum in plasticbonded explosives, except in increasing the heat of detonation.

The blast effect from military high explosives such as TNT has been widely reported [20-22], and the detonation properties of aluminized explosives have been studied in recent years $[10-12,23]$. The chemical processes and the multiphase fluid dynamics that occur within a fireball from of an aluminized explosive are complex. Due to the high pressure and temperature within the combustion products, it is difficult to measure the thermodynamic properties of the multiphase products within the fireball. Therefore, it is convenient to use optical measuring techniques to record the radiant emissions from the fireball. In this work, two aluminized explosive compositions (RDX/A1/AP and $\mathrm{RDX} / \mathrm{Al} / \mathrm{B} / \mathrm{AP}$ ) have been analyzed, and their properties of shock wave overpressure were studied; the highest surface temperature and the dimensions of the explosion fireballs were also determined. The present study provided us with a way of enhancing the blast effect of aluminized explosives in air--

\section{Experimental}

\subsection{Experimental samples}

As indicated earlier, the particle size and the aluminum content influences the performance and sensitivity of the different high explosives. Here, spherical aluminum with a diameter of $2 \mu \mathrm{m}$ and amorphous boron of $1 \mu \mathrm{m}$ size were used in the formulations. SEM photographs of the aluminum and boron powders are shown in Figure 1. 

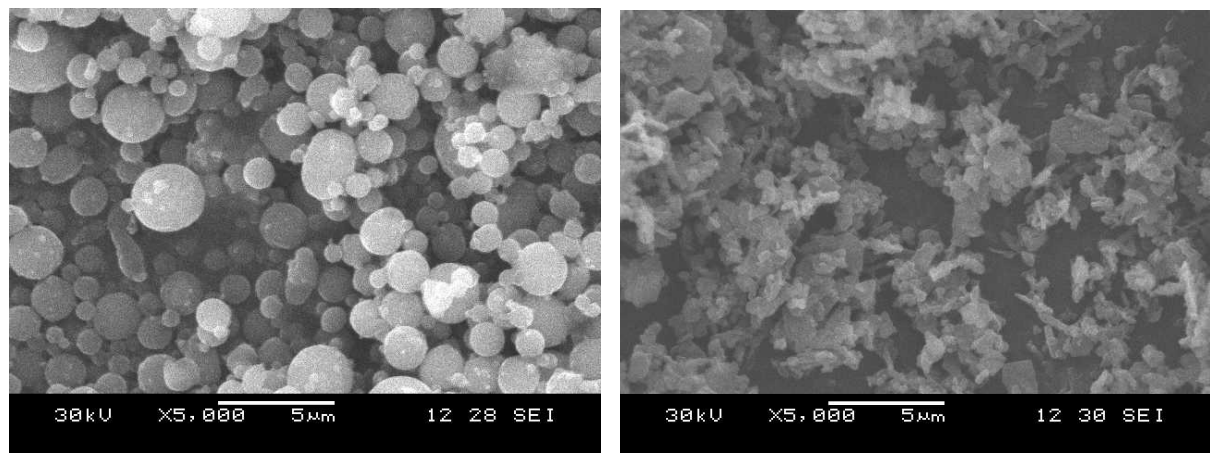

Figure 1. SEM photographs of the aluminum (left) and boron (right) particles.

RDX-based aluminized explosives are hazardous and should be treated in small batches with the proper precautions. These explosive mixtures were made from hexogen (RDX, Gansu Yinguang Chemical Industry Group Co., Ltd., Gansu, China), ammonium perchlorate (AP, Norinco Group Hubei Dongfang Chemical Industry Co., Ltd., Hubei, China), and metal powder (aluminum and boron powders), and held together by microcrystalline wax $\left(\mathrm{CH}_{2}\right)_{\mathrm{n}}$ and other additives e.g. graphite, Qingdao Kropfmuehl Graphite Co., Ltd., Qingdao, China. Commercial grade RDX was used. These explosives contained RDX 36\%, AP $20 \%$, aluminum powder $35 \%$ and the other components $9 \%$ (including graphite $1 \%$ ). The RDX and AP used in these experiments had an average particle size of $30 \mu \mathrm{m}$.

Within this investigation, two different explosive compositions were prepared, and two tests were performed for each type of explosive. The labels and formulations for the aluminized explosives produced are given in Table 1. The quality of the chosen explosive compositions was examined in our previous study and had shown that they have good potential in underwater explosions.

Table 1. Composition of the explosive charges examined (wt.\%)

\begin{tabular}{|c|c|c|c|c|c|}
\hline Sample No. & RDX & Al & B & AP & Others \\
\hline Al-1 & 36 & 35 & 0 & 20 & 9 \\
\hline Al-2 & 36 & 35 & 0 & 20 & 9 \\
\hline Al(B)-1 & 36 & 25 & 10 & 20 & 9 \\
\hline Al(B)-2 & 36 & 25 & 10 & 20 & 9 \\
\hline
\end{tabular}

Fashioned explosive charges (shown in Figure 2), of mass $500 \mathrm{~g}$, were used in the experiments. A 8 \# industrial detonator and a $10 \mathrm{~g}$ booster ( $\Phi 20 \mathrm{~mm} \times 18.5 \mathrm{~mm}$ ) made of phlegmatized RDX were used to initiate the 
explosive charges at the upper end, and the experimental design is shown in Figure 3. The cylinders of the explosives had dimensions of $65.30-73.42 \mathrm{~mm}$ height and $75.00 \mathrm{~mm}$ diameter, and their densities are listed in Table 2.
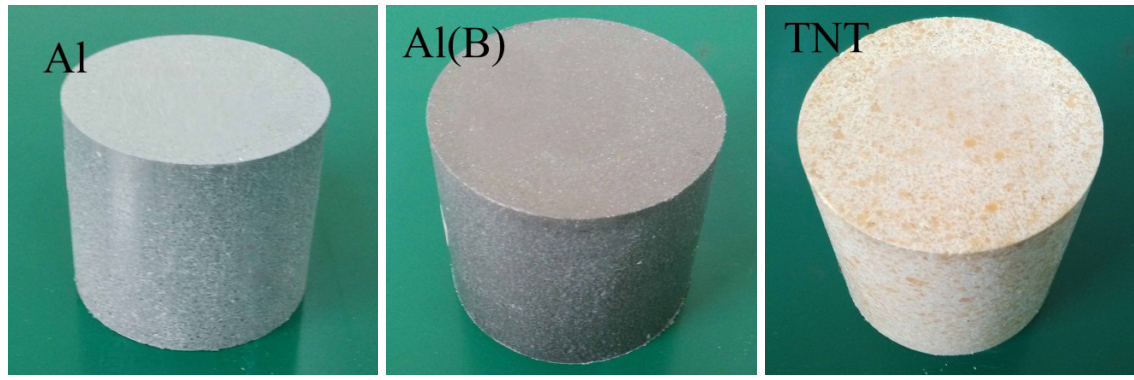

Figure 2. Explosive charges.

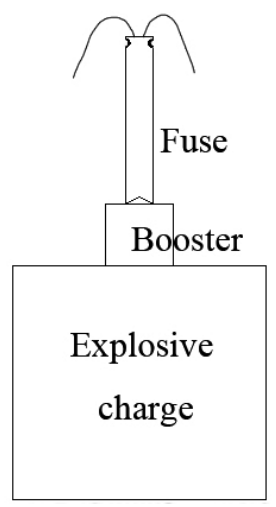

Figure 3. Experimental design.

Table 2. Densities of the explosive charges

\begin{tabular}{|c|c|c|c|c|}
\hline Sample No. & Mass, $[\mathrm{g}]$ & Height, $[\mathrm{mm}]$ & Diameter, $[\mathrm{mm}]$ & Density, $\left[\mathrm{g} / \mathrm{cm}^{3}\right]$ \\
\hline TNT-1 & 500.0 & 73.42 & 75.00 & 1.54 \\
\hline TNT-2 & 500.0 & 73.32 & 75.00 & 1.54 \\
\hline Al-1 & 500.0 & 65.72 & 75.00 & 1.72 \\
\hline Al-2 & 500.0 & 65.58 & 75.00 & 1.73 \\
\hline Al(B)-1 & 500.0 & 65.30 & 75.00 & 1.74 \\
\hline Al(B)-2 & 500.0 & 65.34 & 75.00 & 1.74 \\
\hline
\end{tabular}

\subsection{Experimental instruments and test systems}

The piezoelectric gauges (PCB Piezotronics, Inc., range: $6895 \mathrm{kPa}$, sensitivity ( $\pm 15 \%$ ): $0.145 \mathrm{mV} / \mathrm{kPa}$ ) were located at distances of $3,5,6$ and $7 \mathrm{~m}$ from the 
explosive charge in air and they were used to record the signals of the shock wave overpressure. The charge and pressure sensors were placed at $1.5 \mathrm{~m}$ above the ground. Ground gauges were placed at distances of 2, 3, 4, 5, 6 and $7 \mathrm{~m}$, and were used to measure the parameters of the reflected shock wave overpressure. A schematic diagram of the explosion in air is shown in Figure 4.

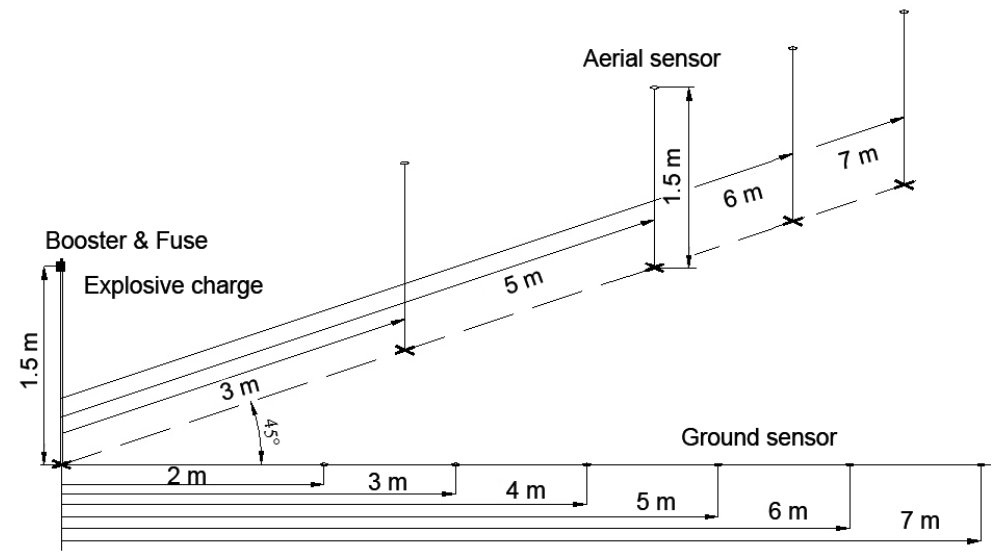

Figure 4. Schematic diagram of the explosion in air.

The spectrometric study of the explosion fireballs was carried out using an infrared thermal-imaging spectrometer (MikroScan 7200V, Mikron Infrared, Inc.). The image of the explosion fireball was obtained using a $2 \mathrm{x}$ Telephoto lens in the spectrometer positioned about $25 \mathrm{~m}$ from the explosion site, which is shown schematically in Figure 5.

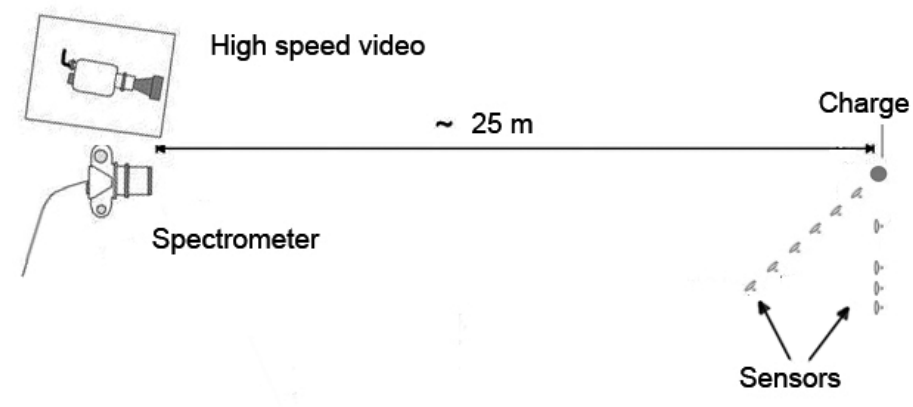

Figure 5. Scheme of the experimental test site. 


\section{Results and Discussion}

\subsection{Shock wave overpressure}

All of the test diagrams of the explosives are similar: after a sharp peak at the beginning, the maximum overpressure decreases rapidly. An illustrative example of the air shock wave overpressure obtained - time diagram for Al-1 at distances of 3, 5, 6 and $7 \mathrm{~m}$ is shown in Figure 6, and the reflected shock wave overpressure - time diagram for Al(B)-1 at distances of 3 to $7 \mathrm{~m}$ is shown in Figure 7.

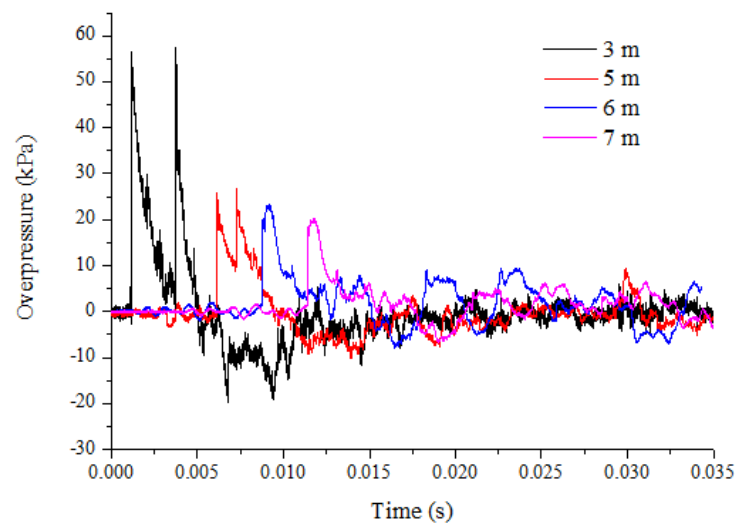

Figure 6. Dependence of air shock wave overpressure for Al-1 at distances of $3,5,6$ and $7 \mathrm{~m}$.

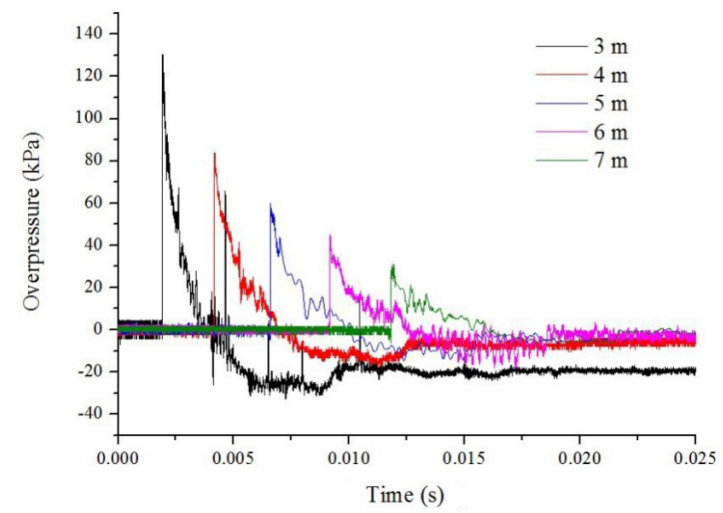

Figure 7. Dependence of reflected shock wave overpressure for $\mathrm{Al}(\mathrm{B})-1$ at distances of 3 to $7 \mathrm{~m}$.

In Figure 6, the reflected shock wave is also obtained. It should be noted that 
the secondary reflected wave does not affect the maximum overpressure value of the primary wave at any measuring point, but substantially affects the value of the overpressure impulses at long distances [24]. The aerial sensors were placed at $1.5 \mathrm{~m}$ above the ground, but placing them at a higher position would cause a larger delay of the reflected wave, and its effect could be eliminated.

For all of the diagrams, the values of the maximum overpressure were determined. They are given in Tables 3 and 4 . Taking the average value, Figure 8 shows the change of the air shock wave overpressure as a function of distance from the charge. Figure 9 shows the relationship between the reflected shock wave overpressure and distance.

Table 3. Maximum air shock wave overpressures for the explosives examined

\begin{tabular}{|c|c|c|c|c|}
\hline \multirow{2}{*}{ Sample } & \multicolumn{4}{|c|}{ Overpressure, $[\mathrm{kPa}]$} \\
\cline { 2 - 5 } & $3 \mathrm{~m}$ & $5 \mathrm{~m}$ & $6 \mathrm{~m}$ & $7 \mathrm{~m}$ \\
\hline Al-1 & 57.93 & 28.86 & 23.40 & 20.46 \\
\hline Al-2 & 57.57 & 27.92 & 23.22 & 20.62 \\
\hline Al(B)-1 & 66.52 & 29.97 & 23.56 & 20.10 \\
\hline Al(B)-2 & 61.36 & 26.44 & 23.01 & 19.61 \\
\hline TNT-1 & 52.43 & 25.09 & 21.35 & 19.22 \\
\hline TNT-2 & 52.65 & 25.41 & 21.53 & 19.77 \\
\hline
\end{tabular}

Table 4. Maximum reflected shock wave overpressures for the explosives examined

\begin{tabular}{|c|c|c|c|c|c|c|}
\hline \multirow{2}{*}{ Sample } & \multicolumn{7}{|c|}{ Overpressure, $[\mathrm{kPa}]$} \\
\cline { 2 - 7 } & $2 \mathrm{~m}$ & $3 \mathrm{~m}$ & $4 \mathrm{~m}$ & $5 \mathrm{~m}$ & $6 \mathrm{~m}$ & $7 \mathrm{~m}$ \\
\hline Al-1 & 307.29 & 134.79 & 87.27 & 62.24 & 47.75 & 28.24 \\
\hline Al-2 & 311.12 & 133.59 & 91.85 & 64.77 & 47.03 & 29.38 \\
\hline Al(B)-1 & 317.44 & 129.91 & 84.22 & 60.74 & 45.81 & 28.79 \\
\hline Al(B)-2 & 342.63 & 124.32 & 85.67 & 63.07 & 48.86 & 29.75 \\
\hline TNT-1 & 319.87 & 119.67 & 74.05 & 55.45 & 37.74 & 21.24 \\
\hline TNT-2 & 332.40 & 125.81 & 82.54 & 52.64 & 41.59 & 23.79 \\
\hline
\end{tabular}




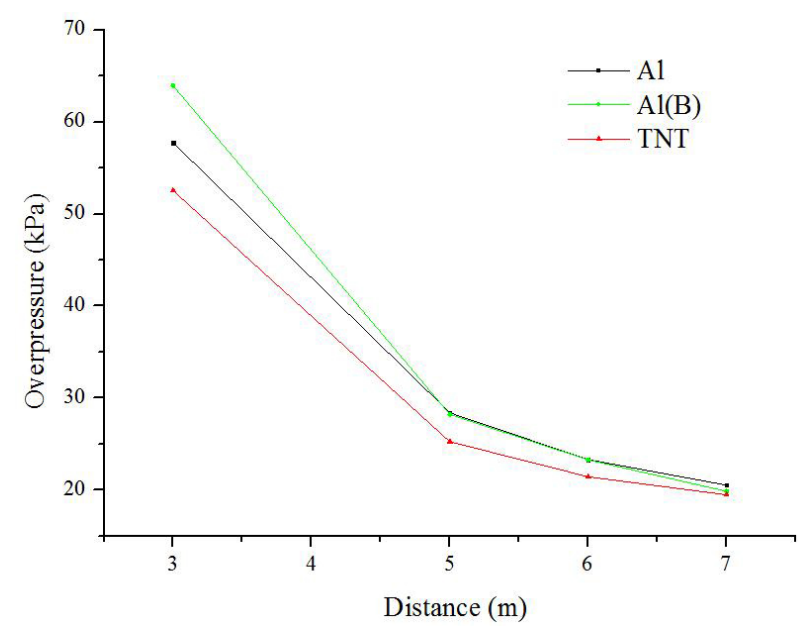

Figure 8. The air shock wave overpressure vs. distance.

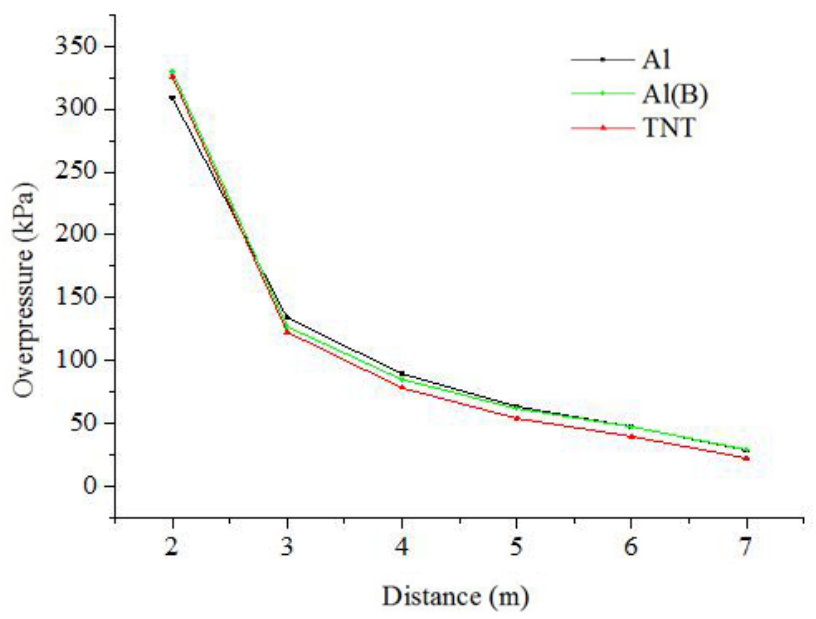

Figure 9. The reflected shock wave overpressure vs. distance.

In Figure 8, there are small differences between the maximum overpressure of the aluminized explosives at the larger distances $(5,6$ and $7 \mathrm{~m})$, while composition $\mathrm{RDX} / \mathrm{Al} / \mathrm{B} / \mathrm{AP}$ produced a higher overpressure than $\mathrm{RDX} / \mathrm{Al} / \mathrm{AP}$ in the region closer to the detonation site $(3 \mathrm{~m})$. Figure 9 also shows a similar pattern. These indicate that it is beneficial to add boron powder to aluminized explosives, in order to enhance the air blast effect in the near explosion field.

A large number of experimental data show that the air blast overpressures generated by a TNT charge can be expressed as follows [25]. 


$$
\Delta p=\frac{p_{1}}{\bar{R}}+\frac{p_{2}}{\bar{R}^{2}}+\frac{p_{3}}{\bar{R}^{3}} \quad(1 \leq \bar{R} \leq 10 \sim 15)
$$

where: $\Delta \mathrm{p}$ is the overpressure, $\mathrm{kPa} ; p_{1}, p_{2}, p_{3}$ are constants; $\bar{R}=R / \sqrt[3]{w}$ is the comparison distance, $\mathrm{m} \cdot \mathrm{kg}^{(-1 / 3)} ; w$ is the mass of the TNT charge, $\mathrm{kg} ; R$ is the distance from the charge, $\mathrm{m}$.

Taking $\bar{R}=R / \sqrt[3]{w}$ as the $\mathrm{X}$-axis and the overpressure as the $\mathrm{Y}$-axis, the air blast overpressure generated by a TNT charge can be fitted by Equation 2 . The overpressure decay of aluminized explosive compositions RDX/Al/AP and $\mathrm{RDX} / \mathrm{Al} / \mathrm{B} / \mathrm{AP}$ can be fitted by Equations 3 and 4, respectively. All of the fitting curves are shown in Figure 10.

$$
\begin{aligned}
& \Delta p=279.37\left(\frac{\sqrt[3]{w}}{R}\right)-1445.32\left(\frac{\sqrt[3]{w}}{R}\right)^{2}+4309.05\left(\frac{\sqrt[3]{w}}{R}\right)^{3} \\
& \Delta p=234.02\left(\frac{\sqrt[3]{w}}{R}\right)-789.25\left(\frac{\sqrt[3]{w}}{R}\right)^{2}+2758.58\left(\frac{\sqrt[3]{w}}{R}\right)^{3} \\
& \Delta p=236.14\left(\frac{\sqrt[3]{w}}{R}\right)-945.40\left(\frac{\sqrt[3]{w}}{R}\right)^{2}+3652.43\left(\frac{\sqrt[3]{w}}{R}\right)^{3}
\end{aligned}
$$

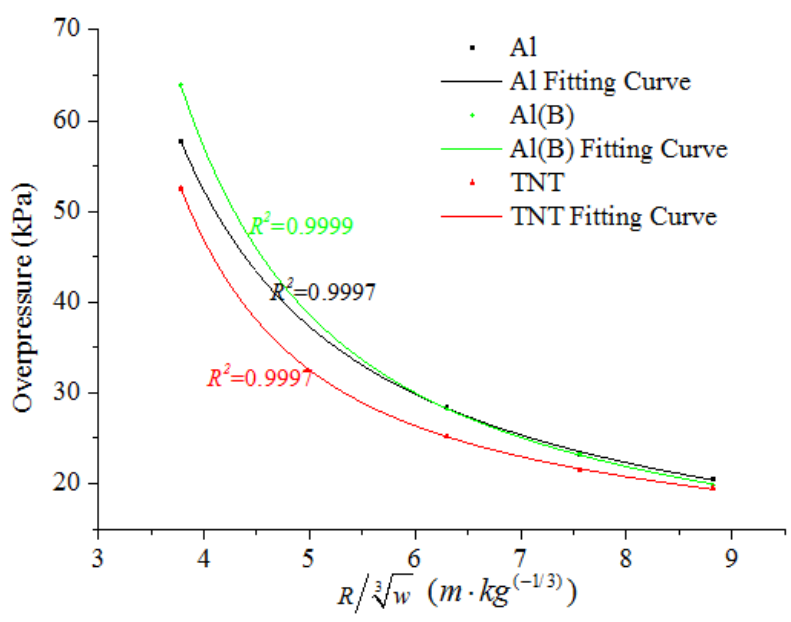

Figure 10. The fitting curves for the explosives examined. 
Substituting the overpressure values of the aluminized explosives into the fitting Equation 2, the TNT mass equivalence of the two compositions can be determined.

Table 4. TNT mass equivalence of the aluminized explosives

\begin{tabular}{|c|c|c|c|c|c|}
\hline \multirow{2}{*}{ Sample } & \multicolumn{5}{|c|}{ TNT equivalence, [kg] } \\
\cline { 2 - 6 } & $3 \mathrm{~m}$ & $5 \mathrm{~m}$ & $6 \mathrm{~m}$ & $7 \mathrm{~m}$ & Average \\
\hline $\mathrm{TNT}$ & 0.50 & 0.50 & 0.50 & 0.50 & 0.50 \\
\hline $\mathrm{Al}$ & 0.57 & 0.72 & 0.66 & 0.64 & 0.65 \\
\hline $\mathrm{Al}(\mathrm{B})$ & 0.65 & 0.70 & 0.66 & 0.56 & 0.64 \\
\hline
\end{tabular}

The TNT equivalence $\left(T N T_{e}\right)$ of an explosive is given [26] by:

$$
T N T_{e}(\%)=100 \times\left(\frac{w_{T N T}}{w_{x}}\right)_{p_{\max }}
$$

where, $w_{x}$ is the mass of the explosive charge and $w_{T N T}$ is the mass of TNT producing the same peak overpressure at the same distance.

Therefore, the TNT equivalence values of the two compositions are $130 \%$ and $128 \%$ respectively.

\subsection{Surface temperature of the fireball}

The MikroScan $7200 \mathrm{~V}$ comes with extensive onboard image processing software as standard. It can be remotely controlled from a PC using optional software, which provides additional analysis and reporting capabilities.

Figure 11 shows the typical infrared thermal images of the aluminized explosives and TNT. It can be concluded that aluminized explosives have a higher surface temperature than TNT at the same time after explosion. The temperature distribution can be clearly seen in these infrared thermal images.

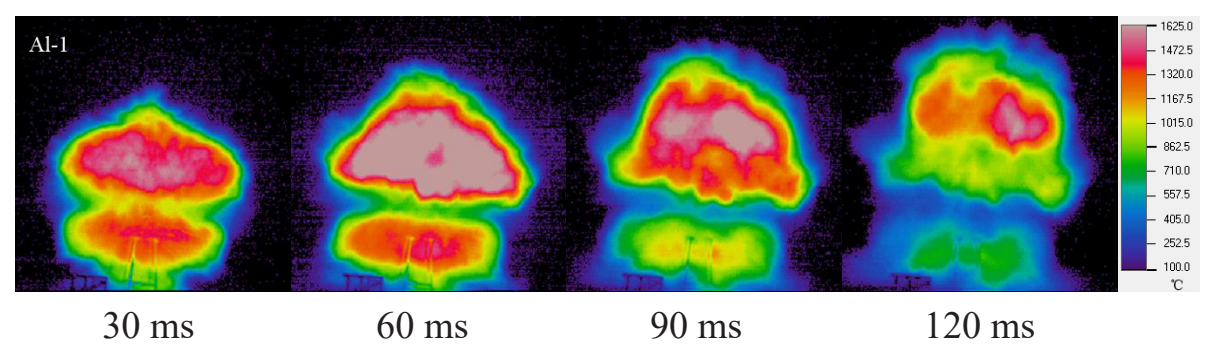



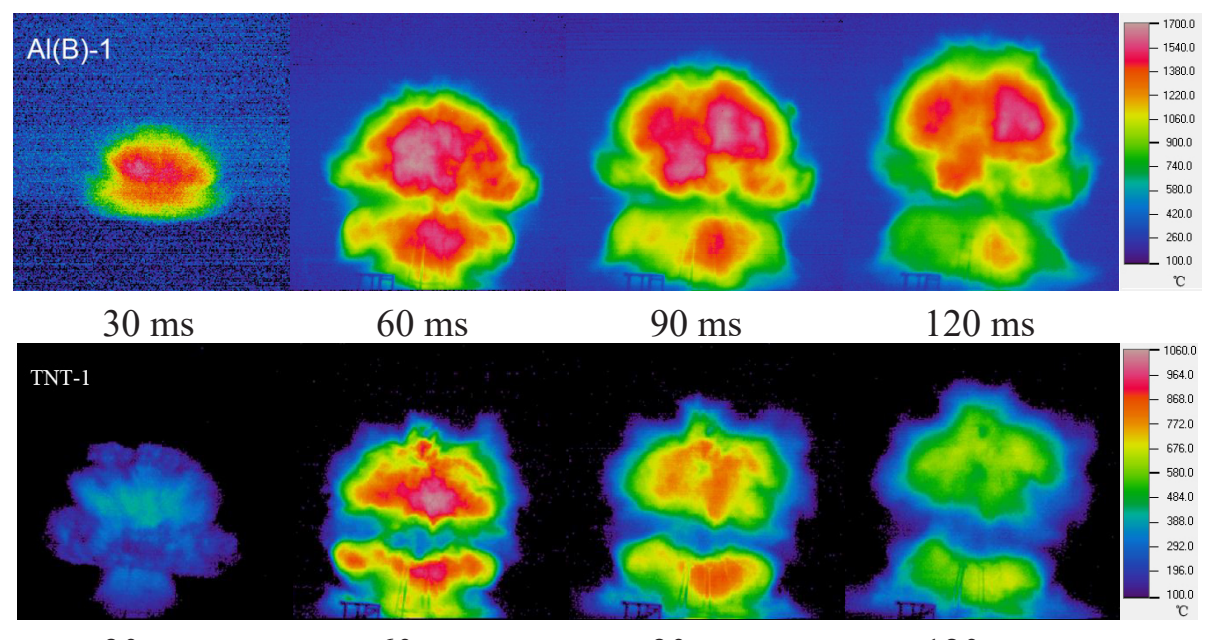

$30 \mathrm{~ms}$

$60 \mathrm{~ms}$

$90 \mathrm{~ms}$

$120 \mathrm{~ms}$

Figure 11. Several infrared diagrams at different times after explosion.

Variations of the highest surface temperature of the fireball with time are shown in Figure 12. Taking the average value of the two examined explosives, the highest surface temperature of the composition $\mathrm{RDX} / \mathrm{Al} / \mathrm{AP}$ was $1602^{\circ} \mathrm{C}$ at about $94 \mathrm{~ms}$ after the explosion; RDX/Al/B/AP was $1683^{\circ} \mathrm{C}$ and TNT $1032^{\circ} \mathrm{C}$ at around $63 \mathrm{~ms}$. It would appear that TNT takes a shorter time than the aluminized explosives to reach the highest surface temperature. In the region of the highest surface temperature above $700{ }^{\circ} \mathrm{C}$, the timescale of the aluminized explosive $\mathrm{RDX} / \mathrm{Al} / \mathrm{AP}$ was about $232 \mathrm{~ms}$, which is 2.73 times that of TNT $(85 \mathrm{~ms})$, with $\mathrm{RDX} / \mathrm{Al} / \mathrm{B} / \mathrm{AP}$ at about $360 \mathrm{~ms}$.

In general, when detonation of an aluminized explosive occurs, due to the high melting point $\left(2054{ }^{\circ} \mathrm{C}\right)$ [27] and/or the mechanical strength of the oxide shell, the aluminum particles react relatively slowly compared to the detonation processes. Aluminum behaves as an inert additive in the reaction zone and is oxidized in the expanding detonation products. This contributes primarily to "late-time effects", such as post-detonation fireballs and detonation temperature [28-30]. Furthermore, because of the secondary oxidation reactions of aluminum with the detonation products, the fireball can maintain a higher temperature for a longer time. Aluminum lies immediately beneath boron in the Periodic Table of the elements and shares many of its chemical properties. However boron has a heat of combustion which is approximately twice than that of aluminum, which means that substituting boron for some of the aluminum powder in an aluminized explosive should be helpful in improving the highest surface temperature of 
the explosion fireball, and in extending the timescale of the high temperature. While for TNT, being an ideal explosive, its explosion can be completed in an instant. Without the secondary oxidation reactions of additives with the detonation products, the temperature of the fireball will decrease very rapidly, and the duration of the high temperature will be relatively short.

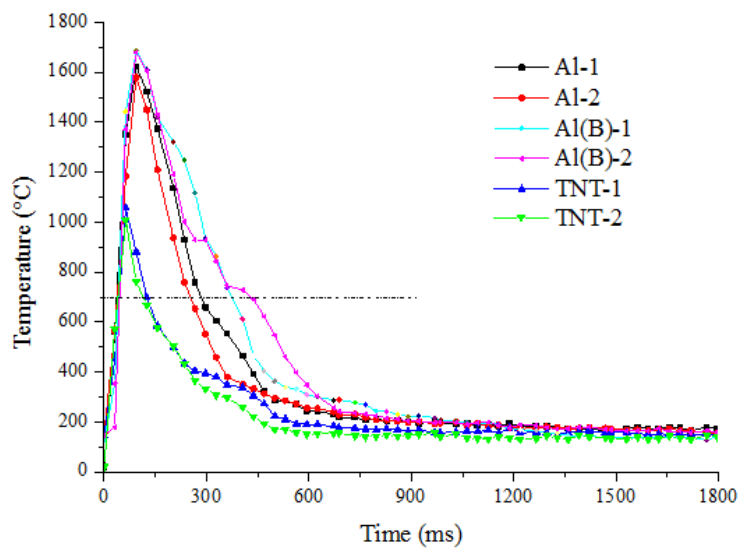

Figure 12. The highest surface temperature of the fireball vs. time.

The detailed surface temperature distribution of the fireball at $60 \mathrm{~ms}$ after the explosion can be obtained from Figure 13. The surface temperature of the fireball had separated into two different high temperature regions. The intermediate region (about $1.5 \mathrm{~m}$ above the ground; the explosive was placed at this height) is relatively low in temperature. Compared to TNT, the high surface temperature region (above $700{ }^{\circ} \mathrm{C}$ ) of the aluminized explosives is larger. Correspondingly the maximum size of the fireball, and the highest surface temperatures from the aluminized explosives are also larger than for TNT.
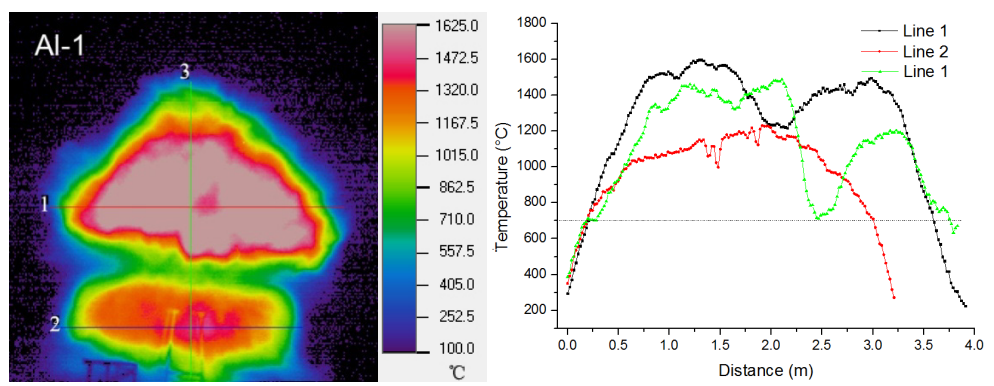

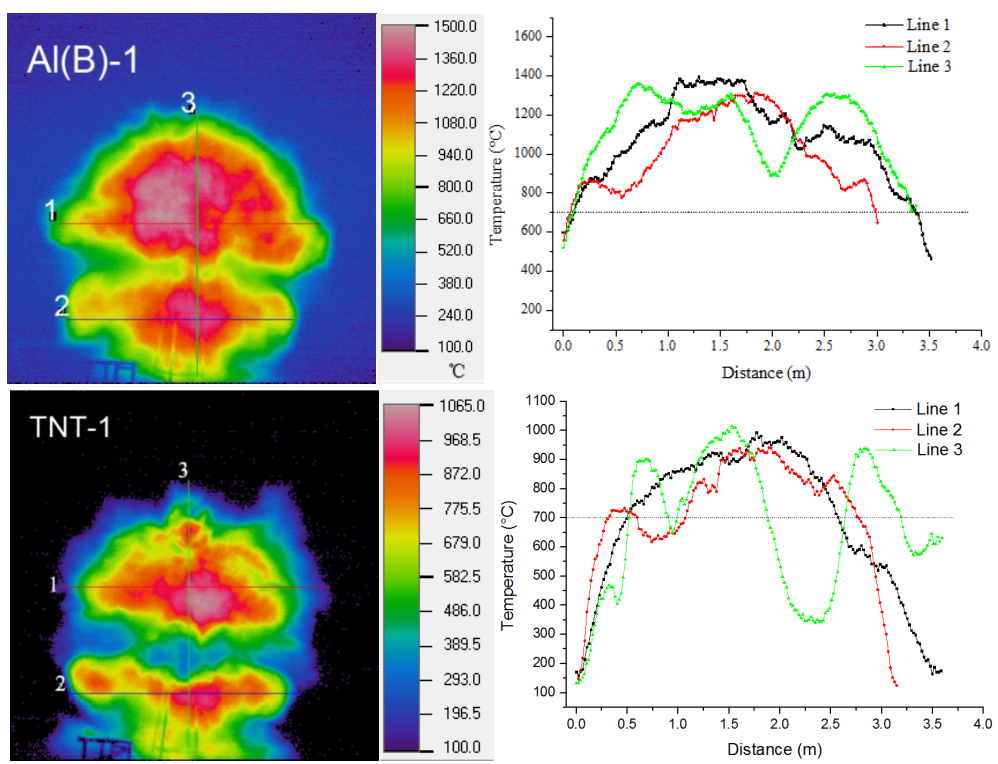

Figure 13. Surface temperature distribution of the examined explosions at $60 \mathrm{~ms}$ and temperature changes with the corresponding plot lines.

\subsection{Dimensions of the fireball}

The dimensions of a fireball can be obtained from the records of the high-speed video and the infrared thermal-imaging spectrometer. High-speed video has been used to record the detonation process of an explosive and to judge the dimensions of the explosion fireball for many years. However most of the explosion tests occur near the ground, and the high-speed video (without a temperature scale) is shot in the visible range, the dimensions of the fireball are affected by the dust raised from the ground. It is hard to distinguish the edges of the fireball. Additionally, the judgment of the dimensions of the fireball is also susceptible to the light intensity of the test environment (shown in Figure 14a). Nevertheless, the infrared thermal-imaging spectrometer can easily estimate the edges of the fireball in accordance with the temperature values (shown in Figure 14b). 


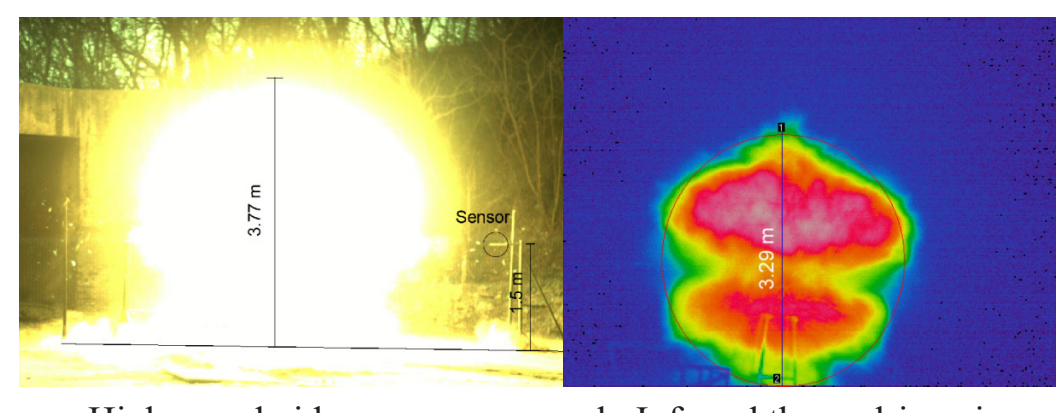

a. High-speed video

b. Infrared thermal-imaging

Figure 14. Judgment of the fireball by different methods (Al-1, $30 \mathrm{~ms}$ ).

An infrared thermal-imaging spectrometer was used to measure the dimensions of the fireball in this work. Using optional software (Lens Calculator) developed by Mikron, a pixel size in an infrared thermal image can be converted to actual dimensions, and thus the size can be determined. In present work, the distance between the spectrometer and the charge was $25 \mathrm{~m}$. According to the results computed by Lens Calculator, the actual dimension of a pixel size was 0.0206 meters in the horizontal and 0.0201 meters in the vertical directions. The distances in Figure 13 were also calculated from these ratios.

Figure 15 provides a way of judging the dimensions of the fireball at different low limit temperatures or different times. By altering the low limit temperatures of the fireball, the dimensions will change simultaneously. Table 5 shows the dimensions of the fireball with different low limit temperatures at $60 \mathrm{~ms}$ after explosion. For the TNT charge, the highest surface temperature was almost reached at this time. These results may be compared to those of the aluminized explosives. The fireball dimensions of the aluminized explosives are obviously larger than those from the TNT charges, especially when the temperature is above $1000{ }^{\circ} \mathrm{C}$. It is should be noted that the surface temperatures from the aluminized explosives reach their highest values at about $94 \mathrm{~ms}$ after explosion. This means that the fireball dimensions from the aluminized explosives may be even larger. Meanwhile, when the low limit temperature is over $1000{ }^{\circ} \mathrm{C}$, the fireballs from $\mathrm{RDX} / \mathrm{Al} / \mathrm{B} / \mathrm{AP}$ are obviously divided into two parts. In this case, the dimension of the fireball should include these two regions. The detailed data are listed in Table 5. 

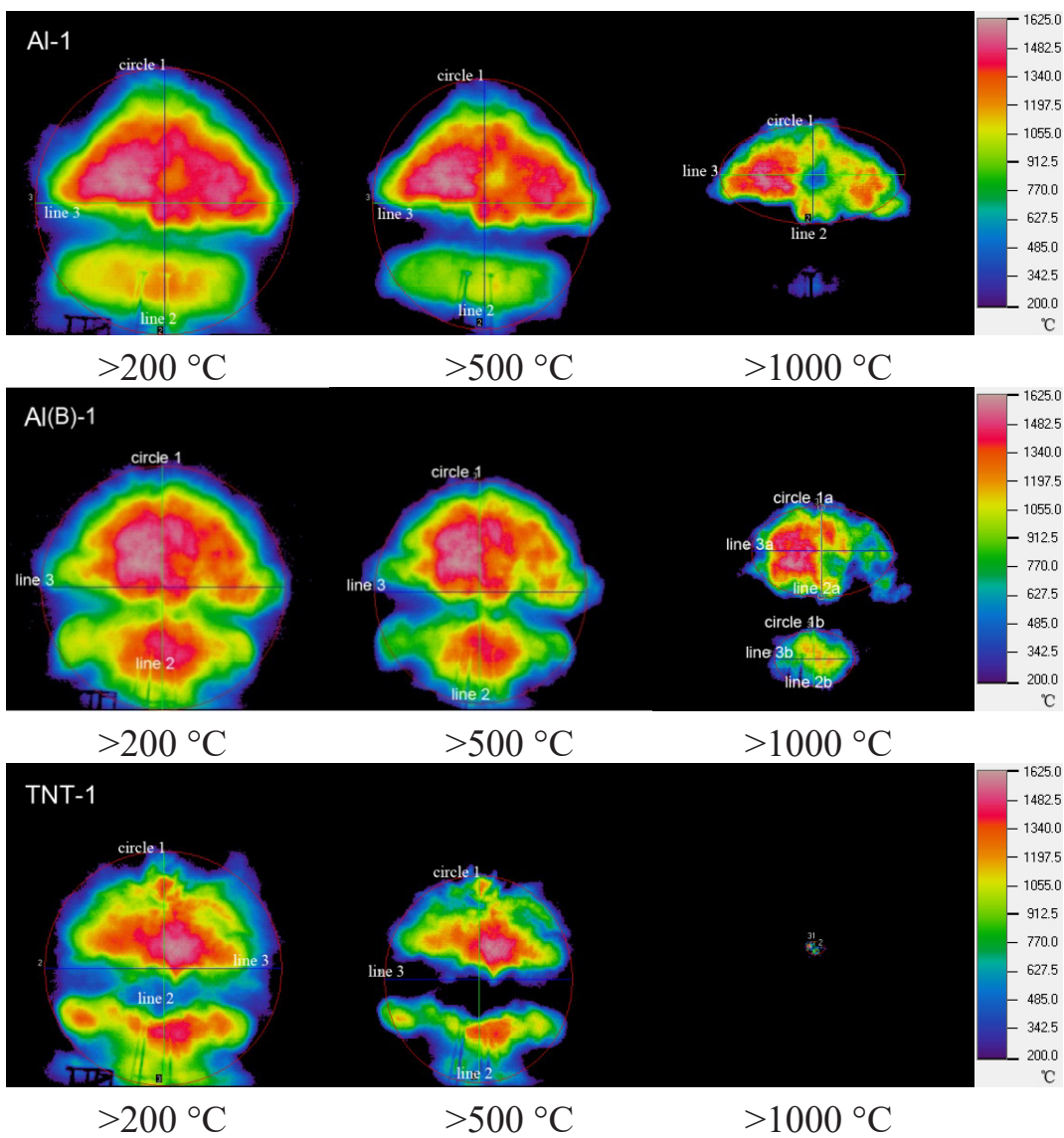

Figure 15. Fireball dimensions from the examined explosives at $60 \mathrm{~ms}$ after detonation.

Table 5. The fireball dimensions of the explosives examined at different temperature regions

\begin{tabular}{|c|c|c|c|c|c|c|}
\hline \multirow{3}{*}{ Sample } & \multicolumn{2}{|c|}{$>200{ }^{\circ} \mathrm{C}$} & \multicolumn{2}{c|}{$>500{ }^{\circ} \mathrm{C}$} & \multicolumn{2}{c|}{$>1000{ }^{\circ} \mathrm{C}$} \\
\cline { 2 - 7 } & $\begin{array}{c}\text { Horizontal } \\
{[\mathrm{m}]}\end{array}$ & $\begin{array}{c}\text { Vertical } \\
{[\mathrm{m}]}\end{array}$ & $\begin{array}{c}\text { Horizontal } \\
{[\mathrm{m}]}\end{array}$ & $\begin{array}{c}\text { Vertical } \\
{[\mathrm{m}]}\end{array}$ & $\begin{array}{c}\text { Horizontal } \\
{[\mathrm{m}]}\end{array}$ & $\begin{array}{c}\text { Vertical } \\
{[\mathrm{m}]}\end{array}$ \\
\hline Al-1 & 3.93 & 3.95 & 3.11 & 3.69 & 2.82 & 1.48 \\
\hline Al-2 & 3.66 & 3.97 & 3.31 & 3.59 & 2.16 & 1.50 \\
\hline Al(B)-1 & 3.73 & 3.64 & 3.21 & 3.30 & 3.38 & 2.17 \\
\hline Al(B)-2 & 3.56 & 3.56 & 3.28 & 3.20 & 3.82 & 1.55 \\
\hline TNT-1 & 3.60 & 3.47 & 2.84 & 3.07 & 0.31 & 0.18 \\
\hline TNT-2 & 3.47 & 3.63 & 2.51 & 2.95 & 0.30 & 0.17 \\
\hline
\end{tabular}




\subsection{Discussion}

Larger scale experiments are being planned to determine the energy release rates for aluminized explosives at later times. Experiments are also being performed to determine whether $\mathrm{H}_{2} \mathrm{O}, \mathrm{CO}$ or $\mathrm{CO}_{2}$ is the most effective oxidizer of aluminum under detonation conditions. These techniques are also being applied to practical $\mathrm{HMX} / \mathrm{AP} / \mathrm{Al}$ or $\mathrm{RDX} / \mathrm{AP} / \mathrm{Al}$ formulations. In these explosives, a complex tradeoff between the AP and aluminum reactions exists. Complete burning of all of the aluminum and boron requires the hot environment to be maintained, which can be achieved by the combustion of the AP. It is much easier to ignite AP at a temperature of $250{ }^{\circ} \mathrm{C}$. AP decomposition produces large amounts of $\mathrm{O}_{2}$ for supporting the burning of the aluminum powder [24, 31, 32]. Aluminum and boron powders act as inert additives in the reaction zone. The secondary oxidation reactions of aluminum and boron with the expanding detonation products contribute to late-time effects, such as the air blast shock wave, postdetonation fireballs and detonation temperature.

\section{Conclusions}

Two compositions of aluminized explosives were developed for an investigation of the effects of boron powder on the air blast properties. These had the following mass compositions: $35 \%$ of metal powders, $20 \%$ of AP, $36 \%$ of RDX, $9 \%$ of wax $\left(\mathrm{CH}_{2}\right)_{\mathrm{n}}$ and other additives. $500 \mathrm{~g}$ charges of the aluminized explosives were prepared and studied.

The maximum overpressure values of the aluminized explosives at all measuring points were higher than those for TNT. The composition containing boron $(\mathrm{RDX} / \mathrm{Al} / \mathrm{B} / \mathrm{AP})$ had a higher overpressure value in the region near the detonation site compared to RDX/Al/AP. The aluminized explosives and TNT charges have a similar attenuation law, and the former exhibited air shock wave overpressures of about 1.3 TNT equivalents.

The highest surface temperature of the explosion fireball from the aluminized explosives was over $1600^{\circ} \mathrm{C}$, which is higher than that from a TNT charge. For the two compositions, $\mathrm{RDX} / \mathrm{Al} / \mathrm{B} / \mathrm{AP}$ had a higher surface temperature, a longer duration of the explosion fireball, and when the surface temperature was above $1000^{\circ} \mathrm{C}$, it had larger fireball dimensions than the other composition. 


\section{References}

[1] Wildegger-Gaissmaier A.E., Aspects of Thermobaric Weaponry, Military Technology, 2004, 28(6), 125-126.

[2] Yen N.H., Wang L.Y., Reactive Metals in Explosives, Propellants Explos. Pyrotech., 2012, 37(2), 143-155.

[3] Cook M.A., Filler A.S., Keyes R.T., Partridge W.S., Ursenbach W., Aluminized Explosives, J. Phys. Chem., 1957, 61(2), 189-196.

[4] Liu R., Yang L., Zhou Z., Zhang T., Thermal Stability and Sensitivity of RDX-based Aluminized Explosives, J. Therm. Anal. Calorim., 2014, 115(2), 1939-1948.

[5] Mishra V.S., Bhagat A.L., Vadali S.R., Singh V.K., Wasnik R.D., Asthana S., Effect of Tungsten on Aluminized Melt Cast High Explosive Formulations, Cent. Eur. J. Energ. Mater, 2012, 9(2), 147-154.

[6] Carney J.R., Miller J.S., Gump J.C., Pangilinan G.I., Time-resolved Optical Measurements of the Post-detonation Combustion of Aluminized Explosives, Review of Scientific Instruments, 2006, 77(6), 63103.

[7] Manner V.W., Pemberton S.J., Gunderson J.A., Herrera T.J., Lloyd J.N., Salazar P.J., Rae P., Tappan B.C., The Role of Aluminum in the Detonation and Post-detonation Expansion of Selected Cast HMX-based Explosives, Propellants Explos. Pyrotech., 2012, 37(2), 198-206.

[8] Gogulya M.F., Dolgoborodov A.Y., Makhov M.N., Brazhnikov M.A., Shetinin V.G., Detonation Performance of Aluminized Compositions Based on BTNEN, $12^{\text {th }}$ Int. Detonation Symposium, San Diego, California, 2002.

[9] Peuker J.M., Krier H., Glumac N., Particle Size and Gas Environment Effects on Blast and Overpressure Enhancement in Aluminized Explosives, Proc. Combustion Institute, 2013, 34(2), 2205-2212.

[10] Trzciński W.A., Cudziło S., Szymańczyk L., Studies of Detonation Characteristics of Aluminum Enriched RDX Compositions, Propellants Explos. Pyrotech., 2007, 32(5), 392-400.

[11] Trzciński W.A., Cudziło S., Paszula J., Studies of Free Field and Confined Explosions of Aluminium Enriched RDX Compositions, Propellants Explos. Pyrotech., 2007, 32(6), 502-508.

[12] Huang H., Huang H.J., Huang Y., Wang X.C., Influence of Particle Size of Aluminum Powder and Morphology of Oxidizer in RDX Based Aluminized Explosive on the Ability of Accelerating Metal (I), Theory and Practice of Energetic Materials, 2003.

[13] Brousseau P., Anderson C.J., Nanometric Aluminum in Explosives, Propellants Explos. Pyrotech., 2002, 27(5), 300-306.

[14] Lefrancois A., Baudin G., Le Gallic C., Boyce P., Coudoing J.P., Nanometric Aluminum Powder Influence on the Detonation Efficiency of Explosives, $12^{\text {th }}$ Int. Detonation Symposium, San Diego, California, 2002.

[15] Shalom A., Aped H., Kivity M., Horowitz D., The Effect of Nanosized Aluminum on Composite Propellant Properties, AIAA Paper, 2005, 3604. 
[16] Brousseau P., Dorsett H.E., Cliff M.D., Anderson C.J., Detonation Properties of Explosives Containing Nanometric Aluminum Powder, $12^{\text {th }}$ Int. Detonation Symposium, San Diego, California, 2002.

[17] Mench M.M., Yeh C.L., Kuo K.K., Propellant Burning Rate Enhancement and Thermal Behavior of Ultra-fine Aluminum Powders (Alex), Energetic Materials - Production, Processing and Characterization, 1998, 30-31.

[18] Simonenko V.N., Zarko V.E., Comparative Studying the Combustion Behavior of Composite Propellants Containing Ultra Fine Aluminum, Energetic Materials - Modelling of Phenomena, Experimental Characterization, Environmental Engineering, 1999, 21.

[19] Lessard P., Beaupre F., Brousseau P., Burn Rate Studies of Composite Propellants Containing Ultra-fine Metals, Energetic Materials - Ignition, Combustion and Detonation, Karlsruhe, Germany, 2001, 81-88.

[20] Baker W.E., Explosion in Air, University of Texas Press, Austin, 1973, p. 281.

[21] Kinney G.F., Graham K.J., Explosive Shocks in Air, Springer, Berlin, New York, 1985, 1.

[22] Swisdak M., Explosion Effects and Properties. Part I. Explosion Effects in Air, DTIC Document, 1975.

[23] Kumar A.S., Rao V.B., Sinha R.K., Rao A.S., Evaluation of Plastic Bonded Explosive (PBX) Formulations Based on RDX, Aluminum, and HTPB for Underwater Applications, Propellants Explos. Pyrotech., 2010, 35(4), 359-364.

[24] Simić D., Popović M., Sirovatka R., Anđelić U., Influence of Cast Composite Thermobaric Explosive Compositions on Air Shock Wave Parameters, Scientific Technical Review, 2013, 63(2), 63-69.

[25] Henrych J., Major R., The Dynamics of Explosion and its Use, Elsevier, Amsterdam, 1979, p. 558.

[26] Haynes W.M., CRC Handbook of Chemistry and Physics, CRC Press, Boca Raton, 2012, p. 2664.

[27] Grishkin A.M., Dubnov L.V., Davidov V.Y., Levshina Y.A., Mikhailova T.N., Effect of Powdered Aluminum Additives on the Detonation Parameters of High Explosives, Combust., Explos. Shock Waves (Engl. Transl.), 1993, 29(2), 239-241.

[28] Victorov S.B., The Effect of $\mathrm{Al}_{2} \mathrm{O}_{3}$ Phase Transitions on Detonation Properties of Aluminized Explosives, 12th Int. Detonation Symposium, San Diego, California, 2002.

[29] Lewis W.K., Rumchik C.G., Broughton P.B., Lindsay C.M., Time-resolved Spectroscopic Studies of Aluminized Explosives: Chemical Dynamics and Apparent Temperatures. J. Appl. Phys., 2012, 111(1), 14903.

[30] Held M., TNT-Equivalent, Propellants Explos. Pyrotech., 1983, 8(5), 158-167.

[31] Tao W.C., Tarver C.M., Kury J.W., Lee C.G., Ornellas D.L., Understanding Composite Explosive Energetics: 4. Reactive Flow Modeling of Aluminum Reaction Kinetics in PETN and TNT Using Normalized Product Equation of State, Lawrence Livermore National Lab., Livermore, CA,USA, 1993.

[32] Jacobs P.W., Whitehead H.M., Decomposition and Combustion of Ammonium Perchlorate. Chemical Reviews, 1969, 69(4), 551-590. 